Article

\title{
Cool City Design: Integrating Real-Time Urban Canyon Assessment into the Design Process for Chinese and Australian Cities
}

\author{
Marcus White ${ }^{1, *}$, Youpei $\mathrm{Hu}^{2}$, Nano Langenheim ${ }^{1}$, Wowo Ding ${ }^{2}$ and Mark Burry ${ }^{1}$ \\ ${ }^{1}$ Melbourne School of Design, University of Melbourne, Melbourne, VIC 3010, Australia; \\ E-Mails:mrwhite@unimelb.edu.au (M.W.),nano.langenheim@unimelb.edu.au (N.L.), mark.burry@unimelb.edu.au (M.B.) \\ 2 School of Architecture and Urban Planning, Nanjing University, 210093 Nanjing, China; \\ E-Mails: youpei.hu@gmail.com (Y.H.), dww@nju.edu.cn (W.D.) \\ * Corresponding author
}

Submitted: 16 April 2016 | Accepted: 9 August 2016 | Published: 12 September 2016

\begin{abstract}
Many cities are undergoing rapid urbanisation and intensification with the unintended consequence of creating dense urban fabric with deep 'urban canyons'. Urban densification can trap longwave radiation impacting on local atmospheric conditions, contributing to the phenomena known as the Urban Heat Island (UHI). As global temperatures are predicted to increase, there is a critical need to better understand urban form and heat retention in cities and integrate analysis tools into the design decision making process to design cooler cities. This paper describes the application and validation of a novel three-dimensional urban canyon modelling approach calculating Sky View Factor (SVF), one important indicator used in the prediction of UHI. Our modified daylighting system based approach within a design modelling environment allows iterative design decision making informed by SVF on an urban design scale. This approach is tested on urban fabric samples from cities in both Australia and China. The new approach extends the applicability in the design process of existing methods by providing 'real-time' SVF feedback for complex three-dimensional urban scenarios. The modelling approach enables city designers to mix intuitive compositional design modelling with dynamic canyon feedback. The approach allows a greater understanding of existing and proposed urban forms and identifying potential canyon problem areas, improved decision making and design advocacy, and can potentially have an impact on cities' temperature.
\end{abstract}

\section{Keywords}

performative urban design; real-time design; sky view factor; urban canyon; Urban Heat Island

\section{Issue}

This article is part of the issue "Sustainable Planning and Technologies", edited by Hatem Ibrahim (Qatar University, Qatar), Ahmed Khan (Université Libre de Bruxelles, Belgium), Steffen Lehmann (University of Portsmouth, UK), Dellé Odeleye (Anglia Ruskin University, UK) and Atiq Zaman (Curtin University, Australia).

(C) 2016 by the authors; licensee Cogitatio (Lisbon, Portugal). This article is licensed under a Creative Commons Attribution 4.0 International License (CC BY).

\section{Introduction}

Many of the world's cities are undergoing rapid urbanisation and intensification (Brenner \& Schmid, 2014; Koolhaas, Obrist, Boeri, Kwinter, \& Tazi, 2001; Rode, 2013) with the unintended consequence of creating dense urban fabric with deep urban canyons. This urban densification can trap longwave radiation having a profound impact on the local atmospheric conditions in particu- lar, the Urban Heat Island (UHI) which can increase temperatures within urban centres considerably when compared to surrounding rural areas (Basara, Basara, Illston, \& Crawford, 2010; Mills, 2004; Oke, 1981, 1988). This heat retention in urban centres has been understood and documented since the late 1960s (Bornstein, 1968), and can cause temperature differences between central urban areas and nearby rural areas ranging from $2{ }^{\circ} \mathrm{C}$ to as much as over $6^{\circ} \mathrm{C}$ on a clear and calm night (US Environ- 
mental Protection Agency, 2008).

Heatwaves are among the deadliest of natural disaster types (Li \& Bou-Zeid, 2013). The death toll in the European heat wave of summer 2003, probably the hottest in Europe since AD 1500, resulted in around 70,000 heat related mortalities (Lass, Haas, Hinkel, \& Jaeger, 2013). Even more extreme heat waves are experienced in Australian cities with recent recorded temperatures in excess of $40{ }^{\circ} \mathrm{C}$ for over five consecutive days (Bureau of Meteorology [BOM], 2013). The already finely balanced climate of Australian cities make them particularly susceptible to impacts of climate change brining heat waves of increased frequency, duration and intensity (Akompab et al., 2013; Patz, Campbell-Lendrum, Holloway, \& Foley, 2005).

Studies by researchers in Nanjing and Shanghai, China found that $\mathrm{UHI}$ is directly responsible for heightened heat-related mortality in urban regions in and around Shanghai (Tan et al., 2010). UHI is a critical issue particularly for cities along the Yangtze River Valley such as Nanjing, which is considered, along with Chongqing and Wuhan, to be one of the "Three Furnaces of China".

$\mathrm{UHI}$ is a key consideration in the design for the growth of cities in the future. As global temperatures are predicted to increase, there is a critical need to better understand urban form and heat retention behaviour in city centres, and to integrate rapid analysis tools into the design decision making process to create cooler cities.

The modelling of UHI is complex (Shao, Zhang, Mi, \& Xiang, 2011) with a great number of variables such as wind, material colour, street orientation, tree coverage, permeability of ground surfaces and building heights in relation to street width or "urban canyon" (Oke, 1988). The urban canyon is where, in dense urban environ- ments, buildings on each side of a street enclose a space obscuring the sky and therefore restricting the amount of long-wave radiation that can escape, a phenomenon particularly acute at night (US Environmental Protection Agency, 2008) (Figure 1).

The urban canyon is considered by many to be the most important contributing factor to the UHI effect (Ibrahim, Nduka, Iguisi, \& Ati, 2011) due to the strong correlation between them (Brandsma \& Wolters, 2012; Kakon \& Nobuo, 2009; Unger, 2009), and is a critical variable considered by microclimate researchers in the study of Urban Heat Island (Ewenz, Bennett, Chris Kent, Guan, \& Clay, 2012). It is the measurement of this variable that is the focus of this paper.

The urban canyon is the degree to which the sky is obscured at a given point commonly calculated as Sky View Factor (SVF) (Johnson \& Watson, 1984), a dimensionless measurement of openness between 0 and 1 , representing totally obscured $\Psi_{\text {sky }}=0$ and totally open spaces $\Psi_{\text {sky }}=1$ where the sky is completely unobstructed allowing all outgoing radiation to radiate freely to the sky (Brown, Grimmond, \& Ratti, 2001).

SVF modelling used to infer UHI is critical to understanding the impact of densification of urban form and if incorporated into the urban design process, has great potential for mitigating future $\mathrm{UHI}$ in developing cities (Grant, Heisler, \& Gao, 2002).

This paper describes the application and validation of a novel three-dimensional modelling approach to calculating SVF, an important indicator used in the prediction of UHI for existing as well as proposed urban design scenarios. A rapid SVF, calculated using a modified daylighting system in a digital modelling and visualisation environment allows iterative design decision making in-

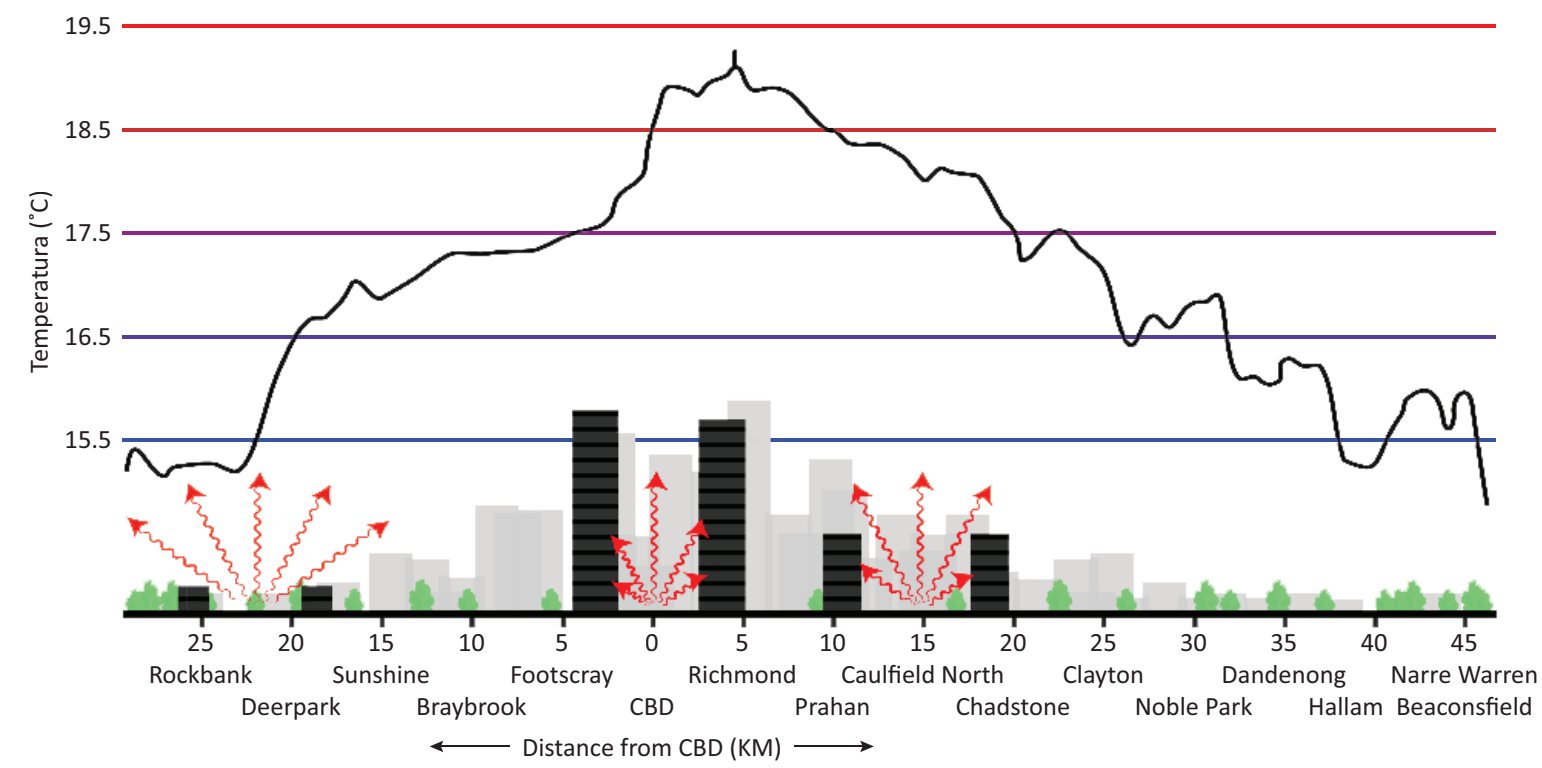

Figure 1. This diagram shows temperature and urban form relationship by way of a longitudinal cross-section through Greater Melbourne overlaid with temperature readings (taken on a clear summer night) from outer western suburbs, through the CBD to the outer south-eastern suburbs (based on diagram from City of Melbourne's Urban Forestry Strategy (Melbourne, 2012)). 
formed by UHI and SVF impacts on an urban design scale. This modelling and analysis approach is tested on urban samples from cities within Australia and China which experience climatic extremes and provide a range of different urban morphologies.

\section{SVF Modelling: Current Methods}

SVF has traditionally been very difficult to measure (Grimmond, Potter, Zutter, \& Souch, 2001). There are however several methods for modelling and assessing SVF manually such as scale model (Oke, 1981), angle measurements, (Bottyan \& Unger, 2003; Johnson, 1985; Johnson \& Watson, 1984), evaluation of fisheye photos (Blankenstein \& Kuttler, 2004; Bradley, Thornes, \& Chapman, 2001; Holmer, Postgård, \& Eriksson, 2001) and evaluation using GPS signals (Chapman \& Thornes, 2004).

SVF can also be calculated computationally using digital elevation model (DEM) databases describing surface geometric elements (Brown et al., 2001; Lindberg, 2005; Souza, Rodrigues, \& Mendes, 2003), and raster-based three-dimensionalisation of two-dimensional data using Digital Elevation Models in GIS (Kokalj, Zakšek, \& Oštir, 2011; Ratti, Baker, \& Steemers, 2005; Ratti \& Richens, 1999). This analysis can be computed rapidly, though as they are two dimensional with a height attribute (2.5D), they cannot assess more complex three dimensional urban forms such as where a street has weather protecting canopies at lower levels or have elements of buildings that may cantilever or protrude from a building at an upper level.

Fully three-dimensional analysis is possible with microclimatic modellers such as SOLWEIG and Envi-Met which can be used to analyse a low detail street canyon to a resolution of $0.5 \mathrm{~m}$ (Levermore \& Cheung, 2012); by using ESRI ArcGIS ${ }^{\text {TM }}$ with the additional add-on package 3D Analyst ${ }^{\mathrm{TM}}$ where hundreds of rays are projected from a series of points (Chen et al., 2012; Kastendeuch, 2013; Kidd \& Chapman, 2012) or by using a similar approach in Rhino with a purpose-built Grasshopper script (Wu, Zhang, \& Meng, 2013). Though effective in analysing complex 3D urban geometry, these methods have been computationally intensive-taking considerable time to assess a precinct (Gal, Lindberg, \& Unger, 2009; Unger, 2009). Though there have been recent improvements in speed, these assessment tools are more suited to simple 3D geometry and are not well integrated with design modelling tools.

\section{Method}

\subsection{GPU and CPU Approach Within Design Modelling Software}

For this study we have used a common 3D design, animation and visualisation program, Autodesk's 3ds Max ${ }^{\mathrm{TM}}$. This software was chosen due to its flexible parametric modelling capabilities, integrated daylight modelling system, and common use in the architectural design industry. Within the program we have developed two variations of a rapid three-dimensional SVF analysis approach which uses a 'hacked' Mental Ray ${ }^{\mathrm{TM}}$ photometric daylight modelling system to create a 'sky dome light'. Our approaches extend Ratti and Richens' (2004) concept of shadow casting on DEM reversing the modelling logic of the aforementioned computational systems, instead of starting with the point of interest and projecting rays outwards to intersect with surrounding geometry and then a hemisphere beyond (Unger, 2009), we use a hemispherical light source-a "sky-dome" or "Skylight Illumination" which projects and traces photons (light) from the globe towards the point of interest. We modified the typical daylight modelling system setting the intensity of the sun to zero (no direct light from the sun as though the sun was turned off), set an artificially low uniform intensity light from the sky (dome). Using this approach, surface areas of the model that received full global illumination (full 180 degrees of light from the hemisphere) appeared white $\left(\Psi_{\text {sky }}=1\right)$. Where the surface is in shadow it appeared as a shade of grey depending on the amount of shadowing of the sky-light by other objects or black where it receives no light $\left(\Psi_{\text {sky }}=0\right)$ (see Figure 2 ).
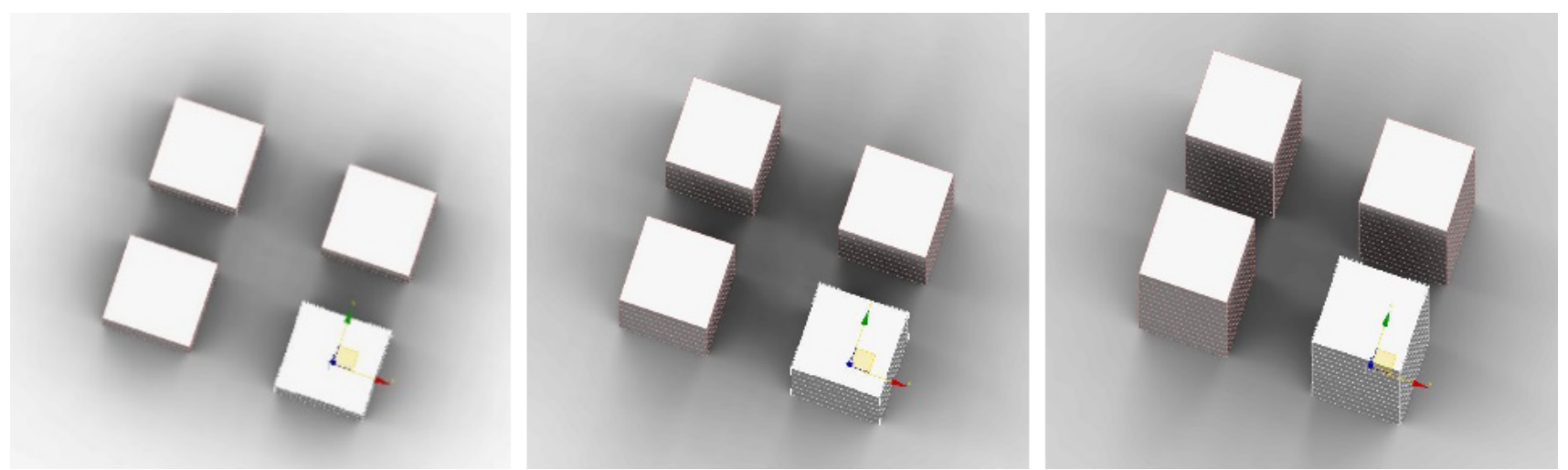

Figure 2. This figure shows a sequence of screen-grabs of four boxes (buildings) with their height parameter changed. As the box's height parameter is increased, the shadows become darker representing a lower SVF reading (less sky is visible where the shadow is darker). 


\section{COGITATIO}

As the Mental Ray ${ }^{\mathrm{TM}}$ render engine within Autodesk 3ds $\mathrm{Max}^{\mathrm{TM}}$ is able to trace millions of photons (Grosch, 2005) this system not only has the advantage of being more accurate but also faster than previous methods, in that we can choose to perform the calculation either using the Central Processing Unit (CPU) or Graphic Processing Unit (GPU).

For numerically quantifiable calculations we used the CPU method which involved reconfiguring a lux level light meter grid calculation system (Reinhart \& Breton, 2009) so as to measure the total amount of sky-dome light hitting each grid point-giving a numeric SVF value (from
$\Psi_{\text {sky }}=0$ to 1 ), as this value can be exported to a .CSV file and opened in Microsoft Excel ${ }^{\mathrm{TM}}$ (or similar spreadsheet program) for further data analysis and quantifiable comparisons of design options (Figure 3 and Figure 4).

This method has been verified through a series of experiments using hemispherical geometry with known percentage areas subtracted comparing expected SVF values with measured SVF values. To verify the accuracy of the SVF meters (reconfigured lux meters), we modelled a series of large mesh domes of different scales and openings. The dome experiment examples included in this paper were modelled with a $300 \mathrm{~m}$ radius. Each of

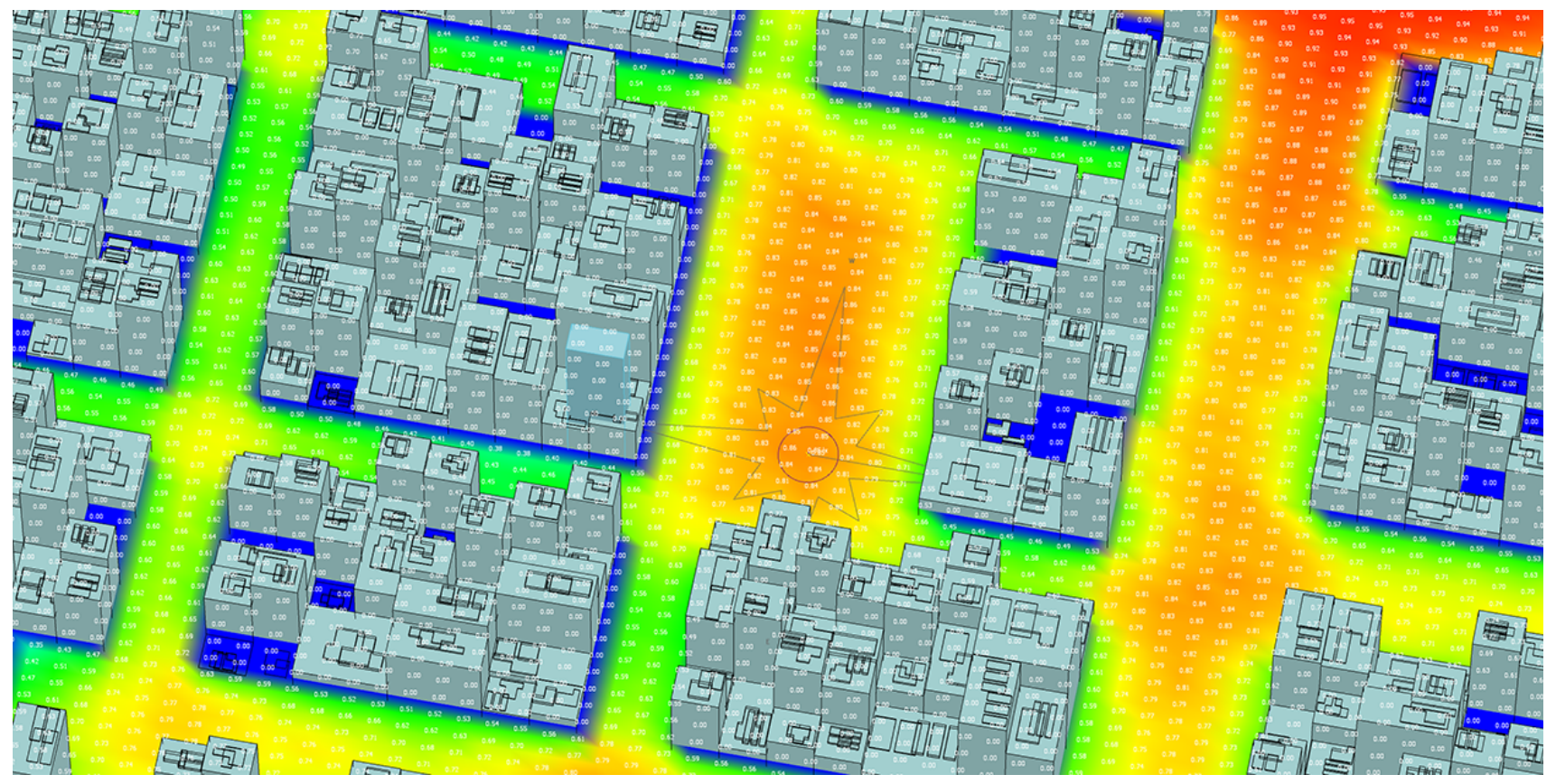

Figure 3. This figure shows a screen grab of the grid of lux meters configured to read SVF levels for a large urban precinct.

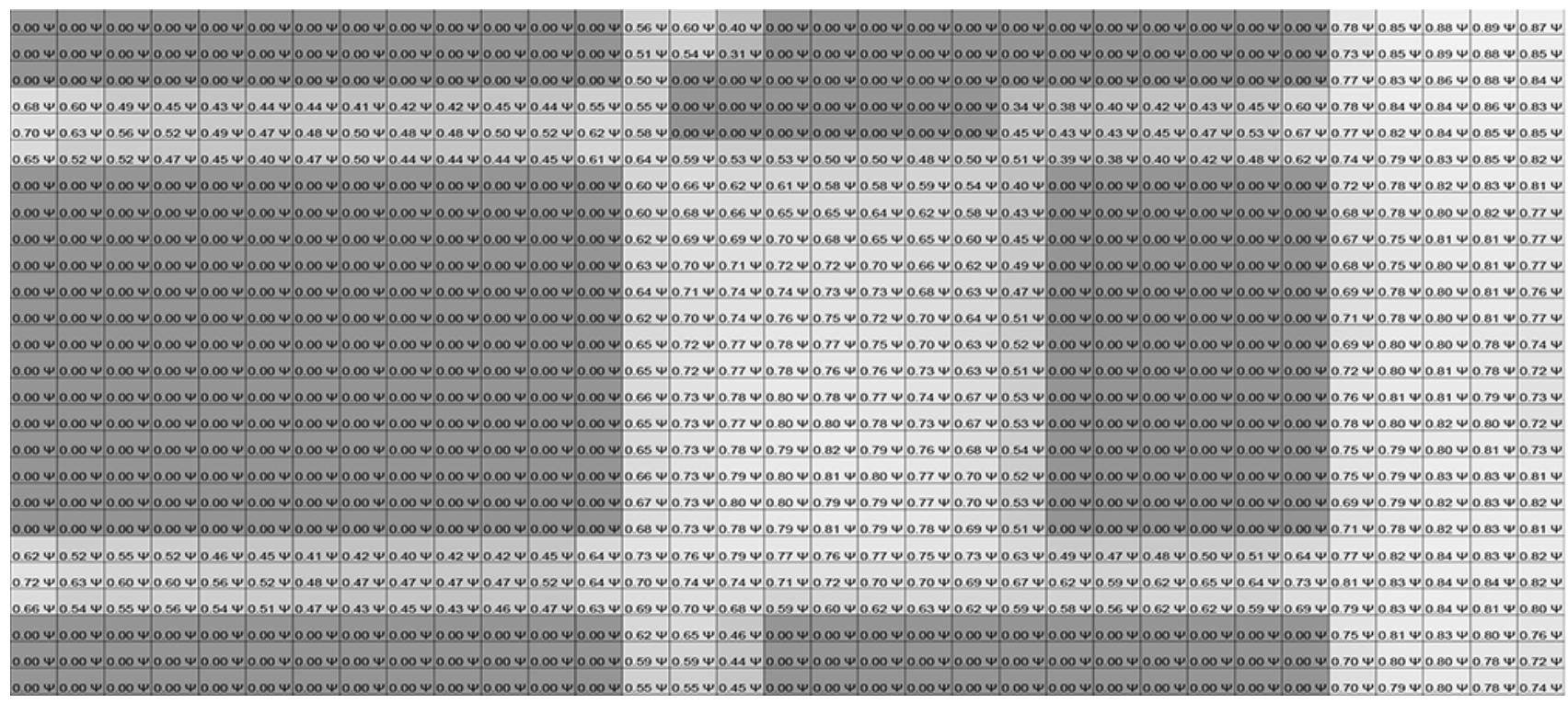

Figure 4. This figure displays a screen grab of a portion of data grid readings exported to Microsoft Excel ${ }^{\mathrm{TM}}$ with cells shaded based on SVF value. Note that inside buildings, SVF $=0$ (this is due to windows and internal walls not being modelled in the test scene). 
these domes was then altered to remove portions of the polygon mesh to a known area percentage-beginning with $50 \%$. We activated the SVF meter and the resulting SVF readings were each within \pm 0.01 of the expected $0.50 \Psi$ reading $(0.51,0.50$ and 0.51$)$ shown in Figure 5 (b), (c) and (d) and Table 1.

We performed the final test with a more complex 3D mesh with a simulated skyline to either retain or remove the dome's polygons (Figure $5(\mathrm{e})$ ). The area of the full dome was measured and compared with the modified skyline dome area. The area comparison showed that $38.883 \%$ of the polygons of the mesh dome retained, thus the SVF meter should result in a SVF $=0.61 \Psi$. In this case the reading was within \pm 0.03 (Table 1 ). This was seen as an acceptable range of error for urban scaled modelling and though a higher degree of accuracy would be possible by increasing the number of photons or the quality of the rendering by increasing the density of light photons, we believed this was not worth the potential sacrifice in speed of feedback.

For more iterative real-time feedback, we used the GPU method which uses the Nitrous ${ }^{\mathrm{TM}}$ viewport drivers (Murdock, 2012) providing a kind of ambient occlusion meaning that this SVF analysis was able to be employed directly within a 3D design modelling environment with real-time viewport feedback (Figures 6 and 7).

\subsection{Urban Sample Studies: Application in Different Urban Conditions}

In this study we examine the validity of the approach by applying the CPU SVF method to four sample areas of existing cities to test speed and ability to produce visually comparable results in vastly different urban conditions. The data can be exported numerically for more detailed analysis or comparison of specific portions of these sample areas. However, this lies outside the scope of this study.

Urban fabric samples of $1000 \times 1000 m$ were selected from areas of the rapidly growing city of Nanjing, China, and one from a growth area in Melbourne, Australia. Sites were chosen that embodied a wide range of urban typologies including tower, towerpodium, slab-block, low-rise high-density (traditional Chinese "hutong" urban form), low-rise low-density (traditional Australian urban form). The sites were also chosen as they are suscep-

Table 1. This table shows the results of verification test examples given in Figure 5, tabling extent of enclosure (as a \% of dome coverage) with expected SVF results against actual SVF point readings. These results suggest a SVF reading accuracy of \pm 0.03 .

\begin{tabular}{llllll}
\hline & $(\mathrm{a})$ & $(\mathrm{b})$ & (c) & (d) & $(\mathrm{e})$ \\
\hline Measured enclosure $(\%)$ & 100.00 & 50.00 & 50.00 & 50.00 & 38.88 \\
Expected SVF $(\Psi)$ & 0.00 & 0.50 & 0.50 & 0.50 & 0.61 \\
Point reading SVF $(\Psi)$ & 0.00 & 0.51 & 0.50 & 0.51 & 0.64 \\
\hline
\end{tabular}

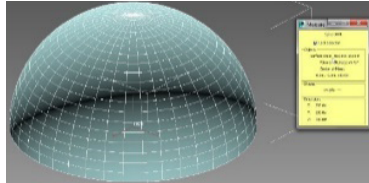

(a) $0.00 \Psi$

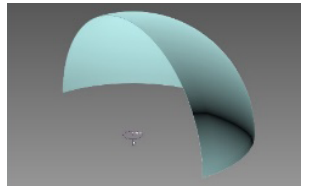

(b) $0.51 \Psi$

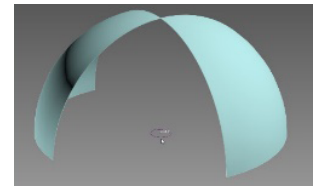

(c) $0.50 \Psi$

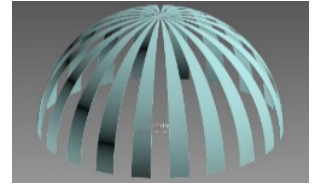

(d) $0.51 \Psi$

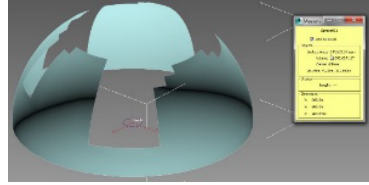

(e) $0.64 \Psi$

Figure 5. This figure gives examples of part of verification testing showing a $300 \mathrm{~m}$ radius dome with known surface area compared with domes of the same radius but different percentages of surface area removed, measuring each with single SVF meter (in the central point of the dome).
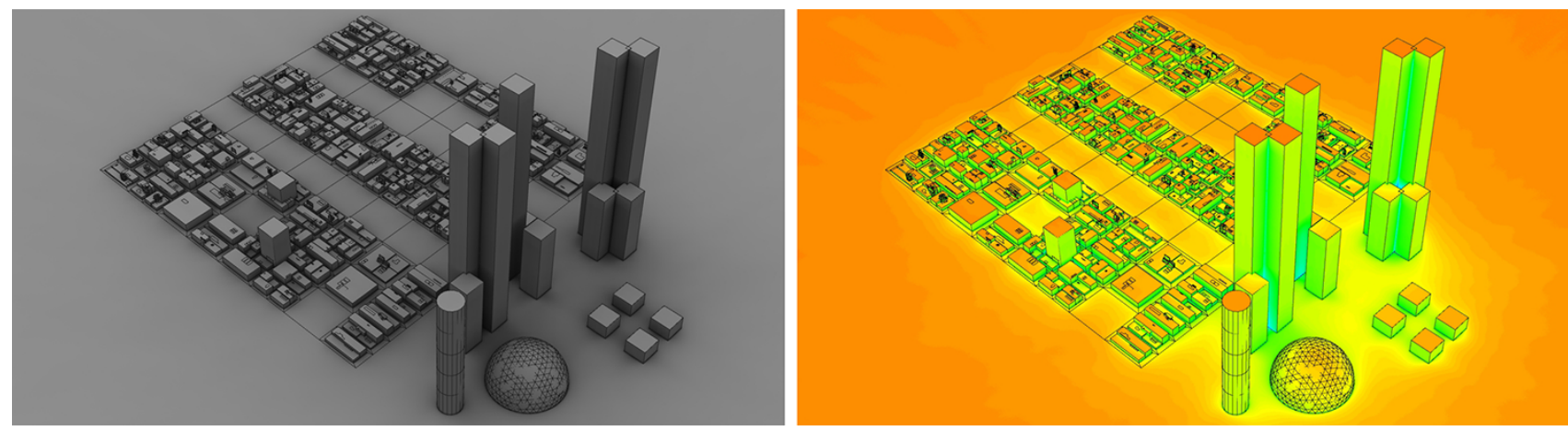

Figure 6. This figure shows screen grabs of a simple precinct model with partially restrictive height limits (low buildings) (left image) with GPU based viewport feedback for sky view factor (urban canyon) of the model on the (right image). 

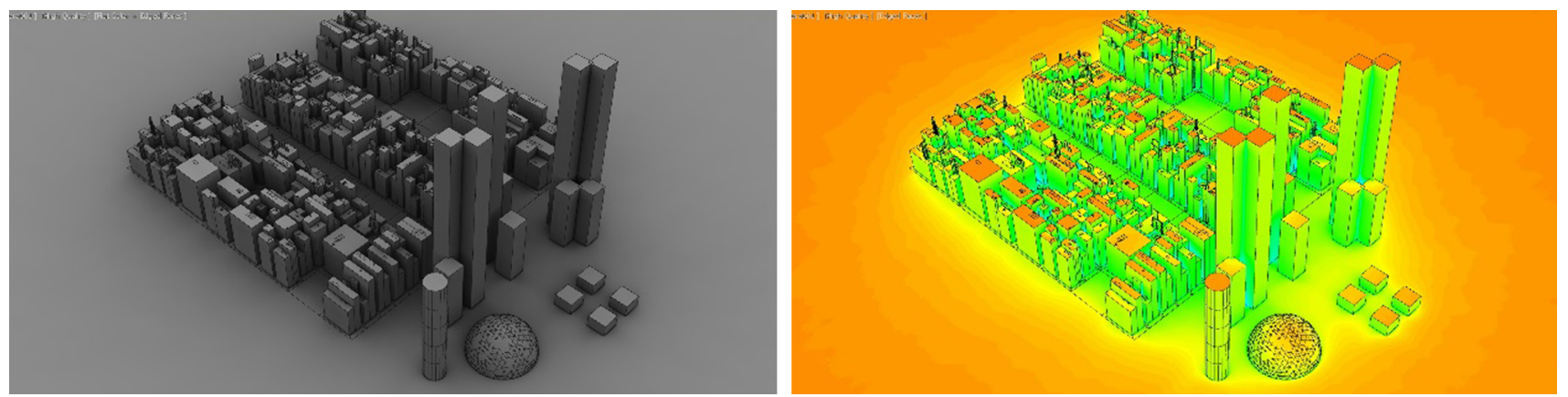

Figure 7. This figure shows screen grabs of a simple precinct model with less restrictive height limits (taller buildings) (left image) with GPU based viewport feedback for sky view factor (urban canyon) (right image).

tible to substantial heat waves (BOM, 2013) and suitable geospatial data was available.

In the second part of the study, we then use the GPU approach on a large urban renewal project testing the method's suitability for comparing existing conditions with the currently proposed master plan, and then compare potential variations of height restrictions and different setback options. For this study we chose Beenleigh, a suburb outside Brisbane, Australia, as it currently in the process of undergoing major urban renewal at a rate and scale similar to Chinese city densities. The chosen site also shares similar climatic heat and humidity conditions to Nanjing China and is therefore a site where increased urban canyon is worthy of consideration in the master planning design process.

\subsubsection{CPU Based SVF Calculation Method Applied}

To test the CPU based SVF calculation, $1000 \times 1000 \mathrm{~m}$ 3D samples of urban form were extracted from existing digital geo-spatial city models of Nanjing, China and

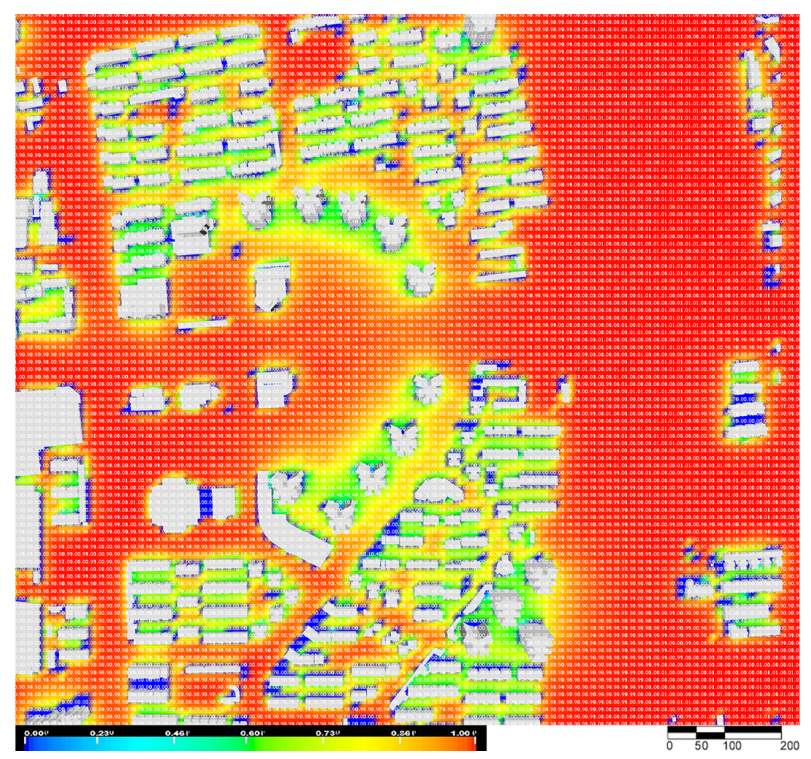

Figure 8. This figure shows Longjiang, a residential area developed in 1990's adjacent to city in Nanjing, China, SVF calculated at $10 \mathrm{~m}$ intervals.
Melbourne, Australia. We sampled Longjiang, a residential area developed in the 1990's adjacent to the Nanjing city, Chengnan, an inner historical area of inner city of Nanjing, Xinjiekou, an inner city Nanjing, and ArdenMacaulay, an inner northern suburb of Melbourne.

We set up a template file with an adapted $1000 \times$ $1000 \mathrm{~m}$ SVF measurement grid set to take measurements at $10 \mathrm{~m}$ intervals. The different square samples were then linked (externally referenced) into the template and the SVF was calculated for each site.

The SVF calculations based on the $10 \mathrm{~m}$ interval settings were obtained extremely rapidly within 10-16 seconds. Light meter intervals at $5 \mathrm{~m}$ were also then tested, generating results within 20-35 seconds and $1 \mathrm{~m}$ intervals generating results within 1.45-3.55 minutes. The site that took the most time to calculate SVF was Changnan, due to the higher polygon mesh density used to represent the finer grain urban form (Figure 10 and Figure 12).

The resulting graphic representational outputs of the analysis draw attention to potential problem urban

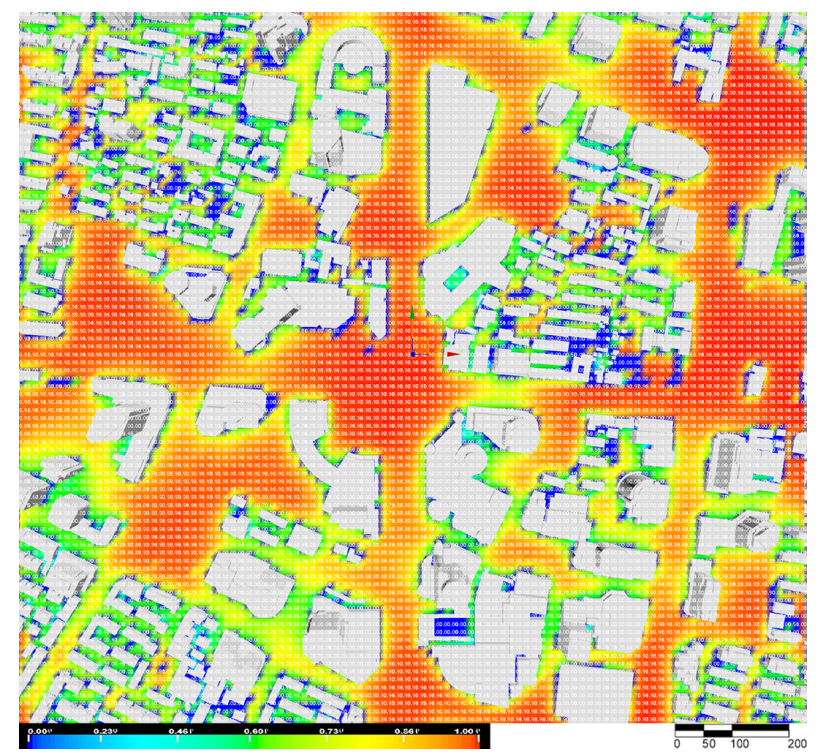

Figure 9. This figure shows Xinjiekou, an inner city Nanjing, China, SVF calculated at $10 \mathrm{~m}$ intervals. 


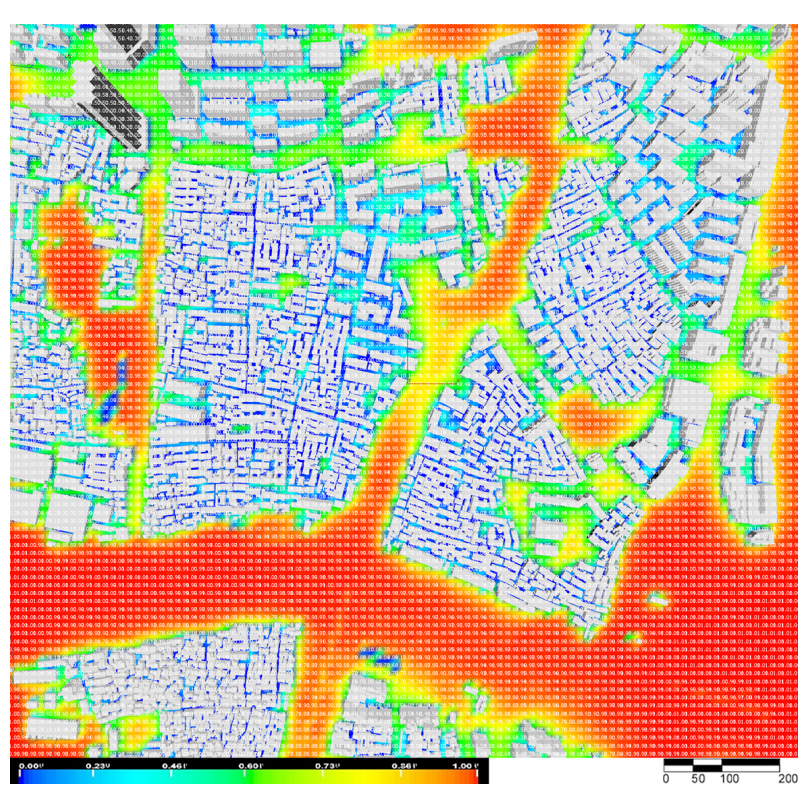

Figure 10. This figure shows Chengnan, an historical area of inner Nanjing, China, SVF calculated at $10 \mathrm{~m}$ intervals.

canyon areas. The visual outputs also allowed quick visual comparisons both between and within the samples. As would be expected in a study of diverse urban forms, a great range of SVF readings were found, with the lowest SVF in the traditional Chinese high-density low-rise urban form in the Chengnan area (Figure 10); the highest readings found in the comparatively low-density low-rise Arden-Macaulay site in Melbourne (Figure 11) and the 1980's modernist developments of Longjiang precinct in Nanjing, China.

As expected, we also found there to be a great variety within each site sample-particularly obvious in

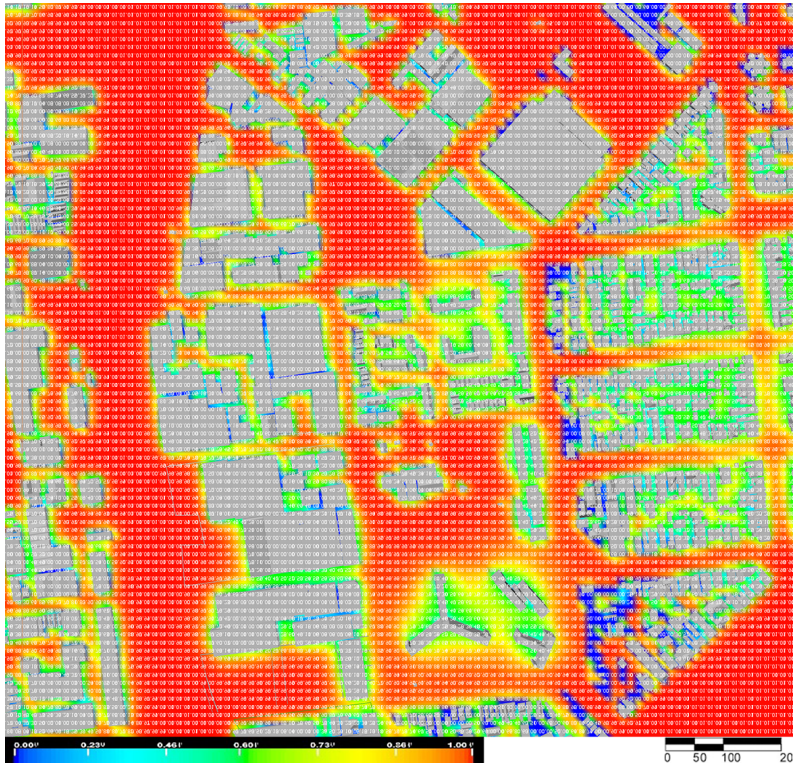

Figure 11. This figure shows Arden-Macaulay, an inner suburb of Melbourne, Australia, SVF calculated at $10 \mathrm{~m}$ intervals.

the Chengnan site (Figure 10 and Figure 12) where traditional low-rise informal Chinese urban forms are contrasted with 1960's Soviet style housing slab-blocks which, somewhat unexpectedly given their heights, achieve considerably better SVF results due to the large adjacent open spaces.

\subsubsection{GPU Based SVF Calculation Method}

The above description of the CPU method shows that the approach is good for analysis of existing conditions and can provide both visual and numeric data output for fur-

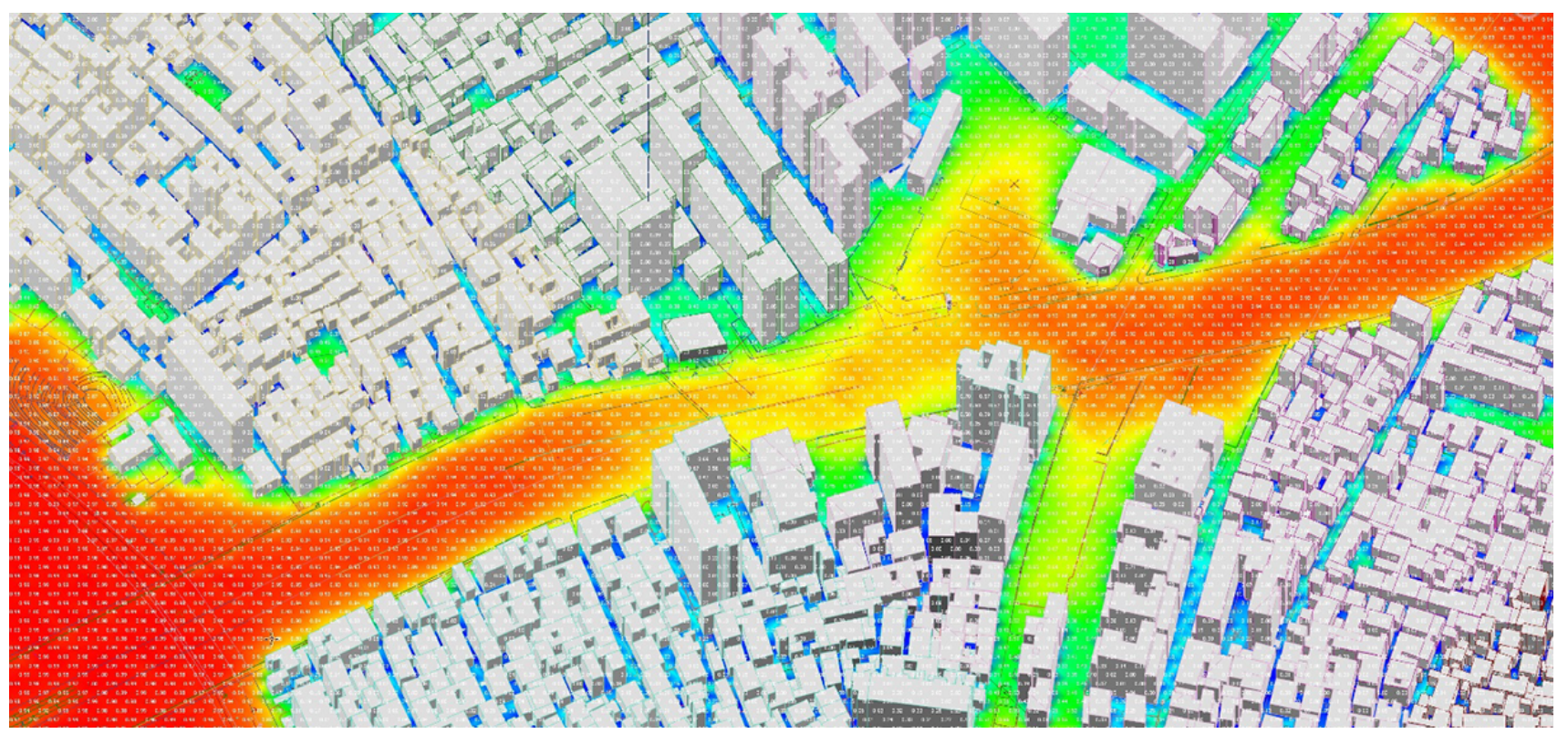

Figure 12. Detailed aerial view of the Chengnan precinct showing contrast between traditional and informal development with Soviet style slab-block development. 
ther analysis, but we hypothesised that a quicker, more iterative process might be more useful for analysis during the design phase of a project.

To test the suitability of the GPU based calculation, we used a used the area of Beenleigh in Queensland, Australia, which is currently undergoing major urban renewal. We tested the existing urban conditions by building a flexible procedural based digital model utilising data from the Logan City Council, and from the online e-research tools of the Australian Urban Research Infrastructure Network (AURIN) (Figure 13, left). We then modelled the potential urban form based on the current government master plan documentation (Figure 13, right).

In this case we embedded (as opposed to externally referenced) the geometry into a single file and managed the existing and proposed design iterations using a 'Scene States' feature which allowed light, cameras, materials, visible layers and geometry parameters to be saved as a 'state'. We set up the GPU based SVF analysis settings on the existing conditions model and saved the Scene State. We then compared the existing conditions with the currently proposed master plan (Figure 14). The GPU based SVF modelling instantly revealed a dramatic reduction in SVF throughout the central activity area in currently proposed master plan option, with the existing urban fabric showing high levels of SVF at both street level and overall building level (shown in red), whereas the proposed master plan model shows low levels at street level (shown in green) and very low levels on façades where proposed high-rise buildings are set out with close proximity (Figure 14).

We then followed on with a series of design variations, changing height parameter restrictions and setback options by adjusting the geometry parameters (Figures 15 and 16). As the 3D model had been set up in a flexible, procedural way, we could rapidly adjust parameters using spinner controllers and receive real-time viewport feedback of not only the impact on SVF, but also on what the new geometry looked like at eye height (visual impact) using perspective cameras and by toggling between Scene States from SVF state to textured viewport state. As we were calculating SVF with the GPU method, the analysis was considerably faster than the CPU method, that would allow for a more integrated and iterative design workflow whilst developing planning controls for the site. The analysis also calculated SVF for not only the ground level as would be the case for other SVF analysis methods mentioned earlier, but also assessed façades and building roofs (Figure 16).

\section{Conclusion}

In this paper we have outlined preliminary findings of a new method for modelling SVF that extends the applicability of the metric by proposing two analysis methodsa CPU based calculation and GPU base calculation. Both of these methods dramatically increase speed of analysis, addresses limitations of 2.5D methods of SVF calcu-
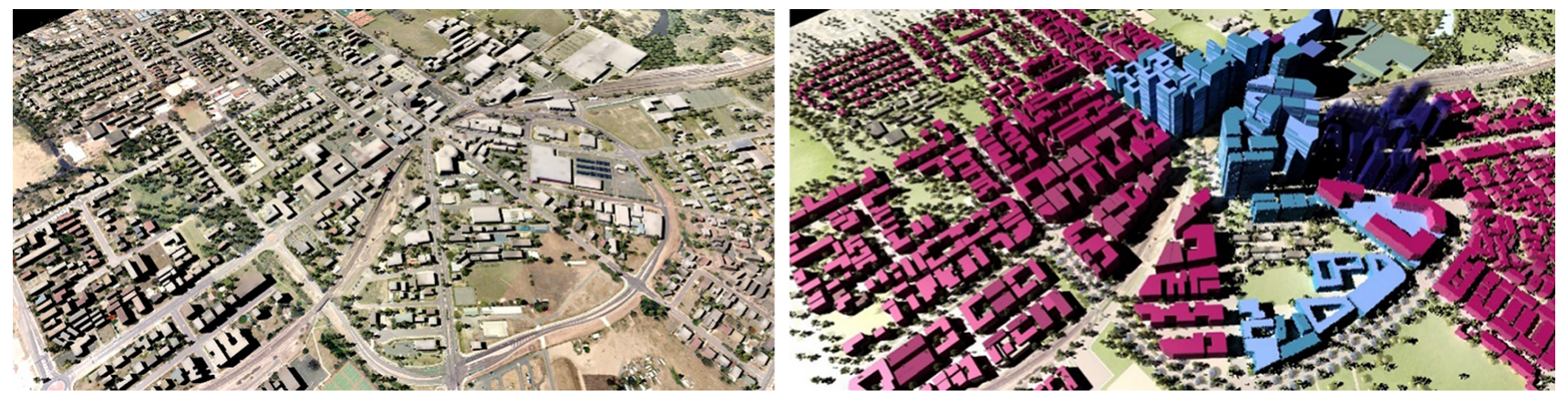

Figure 13. Left image shows render of 3D digital model of existing urban form. Right image shows render of flexible 3D digital model of master plan's potential urban form, used for visualisation; communication; solar impact analysis; and design advocacy.
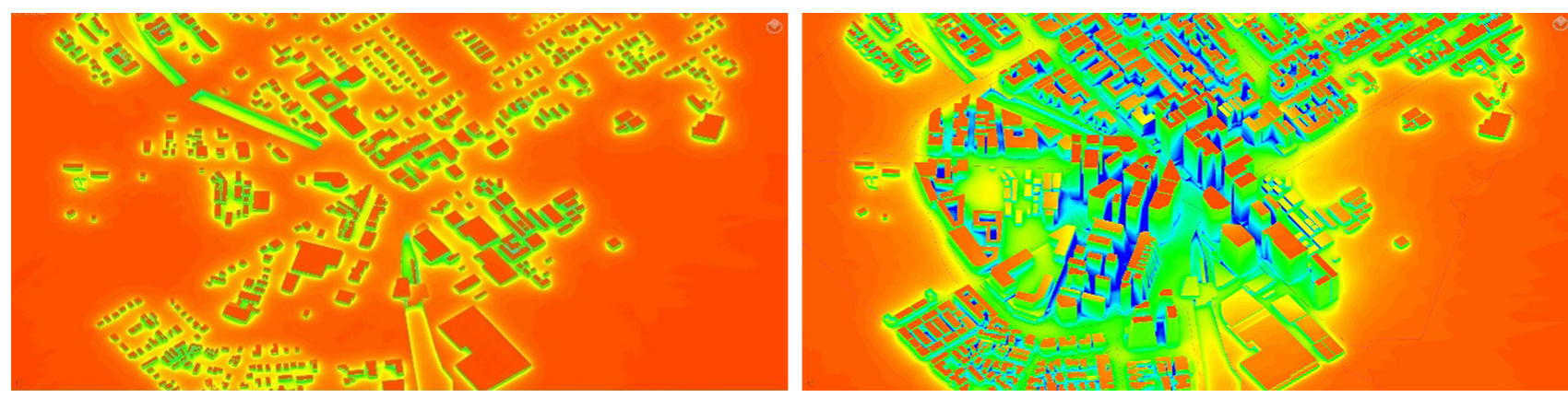

Figure 14. Left: screen grab of GPU based SVF calculation performed on the town centre of Beenleigh, in the City of Logan, Queensland, Australia. Right: GPU based SVF calculation performed on currently proposed master plan height and setbacks, resulting in clearly visible increased urban canyon (low level of SVF shown in blue). 

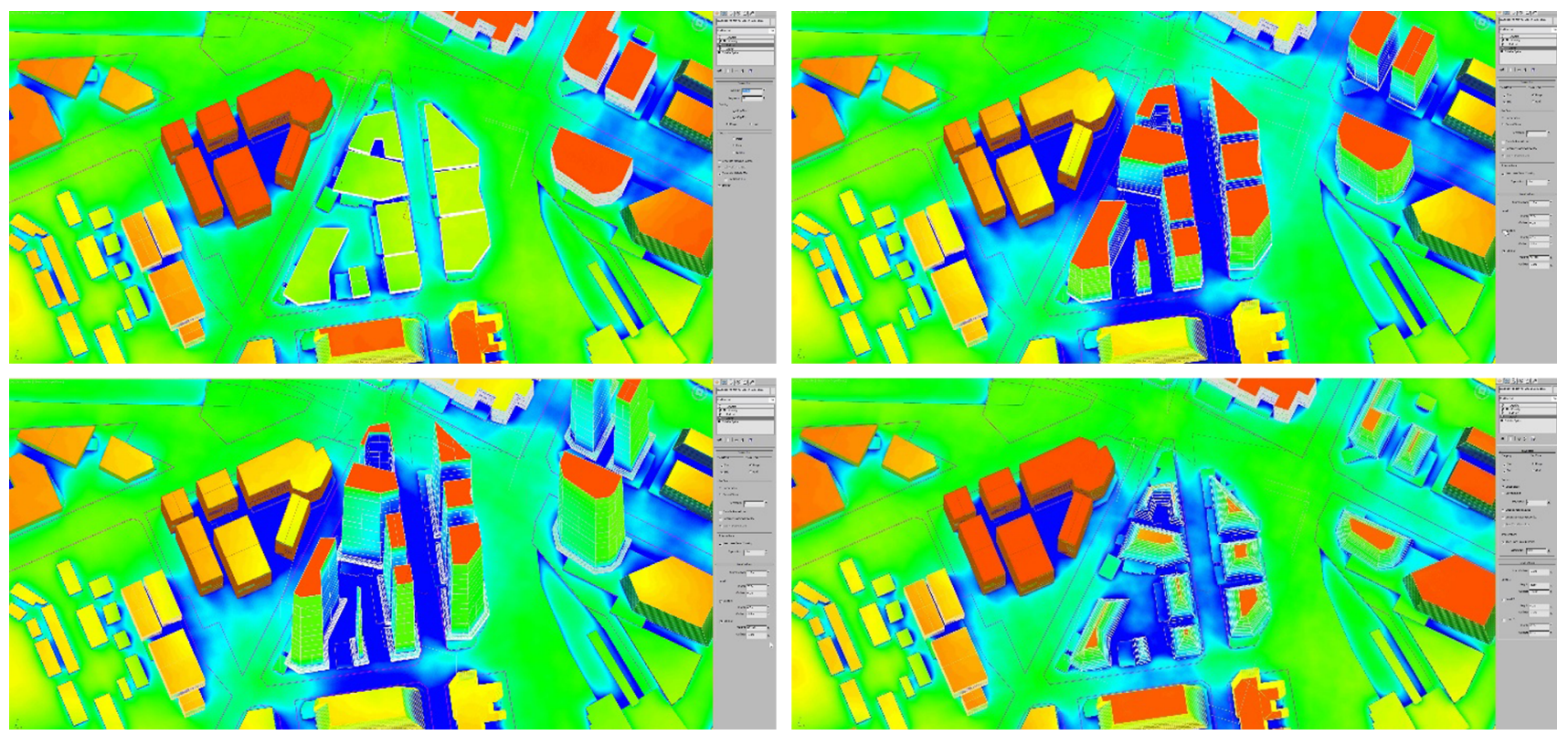

Figure 15. A series of screen grabs showing GPU based SVF calculated in real-time whilst adjusting height, podium size and setback, and tower taper parameter 'spinners' controlling potential urban form.

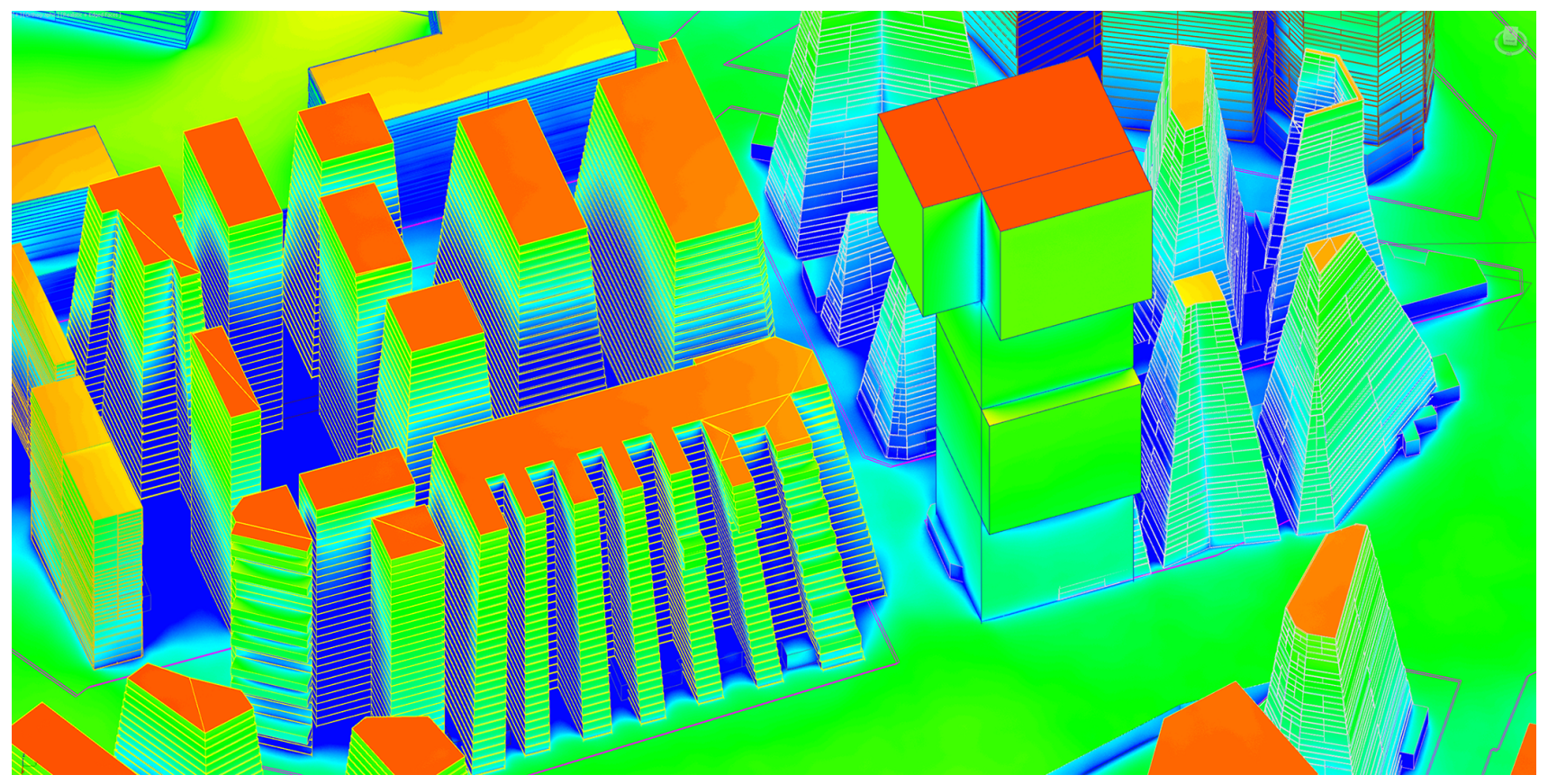

Figure 16. This figure shows a screen grab illustrating the detailed 3D SVF calculation on potential urban form with tapering setback profiles, as well as more complex cantilevered balconies and building masses. The SVF is not only calculated at the ground level, but also across building façades (potentially useful for assessing view quality within buildings).

lation and integrate the analysis into design software to provide rapid design feedback.

The CPU based calculation was shown to be useful in studies of existing urban fabric, where a known physical condition can be tested and compared with other existing urban fabrics (Figure 8 to Figure 11). Though typology was not the focus of this study, the SVF modelling approaches rapidly exposed the large variation in openness in each of the study areas with particularly interesting resulting comparisons with low-rise traditional Chinese areas compared with modernist mid-rise slab block hous- ing (Figure 10). The results of these initial tests suggest further investigation of urban morphology and typological impacts of SVF looking at each of the sites in more detail and comparing numeric SVF data outputs with microclimatic readings. Though SVF is only one piece of the puzzle of UHI modelling, it is an important element to understand and be able to analyse at a large but detailed scale. The modelling approach outlined provides city designers and researchers potential for complex and detailed comparative studies of large scale SVF readings against environmental behaviour within test areas using 
temperature and humidity sensor data logging (Ewenz et al., 2012; Kakon \& Nobuo, 2009) and is part of ongoing parallel micro climatic research by the authors (White \& Kimm, 2015) as well as vegetation impact modelling research (White \& Langenheim, 2014a).

The CPU method appears useful in identifying key problem areas in existing urban conditions, suggesting where urban design interventions or solutions might be most effectively targeted either through modification of urban form, or where this is not possible, through strategically located vegetation.

The GPU based calculation method proved to be useful in a more fluid and tactile way due to its real-time feedback combined with real-time model manipulation. By providing dynamic visual (viewport) SVF feedback for complex three-dimensional urban scenarios, it permits new ways of engaging feedback during design processes, effectively integrating the design analysis with the design process. As this method remains within the design modelling and visualisation environment, it lends itself to mixing intuitive compositional design gestures, cultural understandings and conceptual design ideas with meaningful environmental impact feedback. This differs from other algorithmic optimisation modelling approaches (Panão, Gonçalves, \& Ferrão, 2008; Yu, Austern, Jirathiyut, \& Moral, 2014) in that it does not attempt to remove the human element of design. There is however potential for further investigation of using either CPU or GPU based SVF analysis methods in the exploration of optimisation algorithms using MaxScript or Max Creation Graph, or by porting the approach to Rhino 3D with Grasshopper.

In large scale urban renewal projects, we see great potential for designers to use both the GPU and CPU based analysis as an integrated part of their design process. GPU based SVF can be used whilst 'form finding' as urban form is manipulated and 'sculpted' to maximise SVF whilst meeting a variety of other design criteria. Urban planning control options can be compared visually with GPU method, and when design options are refined, the CPU based numeric analysis can be used to calculate tangible numeric evidence that can be used in the advocacy of design propositions.

Both CPU and GPU approaches have the potential to inform existing and new planning controls for renewal areas. The above studies suggest that planning controls such as site coverage, building setbacks and building heights might be informed using these approaches in cities that experience extreme heat conditions where urban canyon is considered a critical decision making factor such as those cities sampled above.

The method described also has potential for assessment of other aspects of urban comfort. As mentioned above, the GPU method calculates SVF at ground level as per the CPU method and other commonly used SVF analysis methods, but also assesses façades and building roofs. There is potential for further research into the impact of SVF on the quality of view within high density development. This raises questions such as: does the amount of sky visible from a façade (apartment windows or balconies) impact on property prices; and does the amount of visible sky from within a hospital room impact on patient recovery times?

In conclusion, the new approach extends the applicability in the design process of existing methods by providing 'real-time' SVF feedback for complex threedimensional urban scenarios in a variety of diverse urban contexts. The modelling approach enables city designers to mix intuitive sculptural, compositional and tactile design modelling with dynamic urban environmental modelling feedback, and output numeric data when required.

The approach allows a greater understanding of existing and proposed urban forms and identifying potential UHI problem areas; improved decision making, community engagement and design advocacy; and can potentially have an impact on cities' temperature thus reducing cooling energy load costs, and more importantly, potentially reduce heat related mortality.

\section{Acknowledgments}

The research has in part been funded by a University of Melbourne ECR grant, the AURIN Lens10 project for innovative urban design, and supported by the Chinese National Science Foundation (51108228). This paper extends initial preliminary research described in the 2014 ISUF conference (White \& Langenheim, 2014b).

\section{Conflict of Interests}

The authors declare no conflict of interests.

\section{References}

Akompab, D. A., Bi, P., Williams, S., Grant, J., Walker, I. A., \& Augoustinos, M. (2013). Heat waves and climate change: Applying the health belief model to identify predictors of risk perception and adaptive behaviours in Adelaide, Australia. International Journal of Environmental Research and Public Health, 10(6), 2164-2184.

Basara, J. B., Basara, H. G., Illston, B. G., \& Crawford, K. C. (2010). The impact of the urban heat island during an intense heat wave in Oklahoma City. Advances in Meteorology, 2010.

Blankenstein, S., \& Kuttler, W. (2004). Impact of street geometry on downward longwave radiation and air temperature in an urban environment. Meteorologische Zeitschrift, 13(5), 373-379.

Bureau of Meteorology. (2013). 2013 shaping up to be one of Australia's hottest years on record. Bureau of Meteorology. Retrieved from http: //www.bom.gov.au/climate/updates/articles/a0032013-temperature.shtml\#july-update

Bornstein, R. D. (1968). Observations of the urban heat island effect in New York City. Journal of Applied Meteorology, 7(4), 575-582. 
Bottyan, Z., \& Unger, J. (2003). A multiple linear statistical model for estimating the mean maximum urban heat island. Theoretical and Applied climatology, 75(3/4), 233-243.

Bradley, A., Thornes, J., \& Chapman, L. (2001). A method to assess the variation of urban canyon geometry from sky view factor transects. Atmospheric Science Letters, 2(1/4), 155-165.

Brandsma, T., \& Wolters, D. (2012). Measurement and statistical modeling of the urban heat island of the city of Utrecht (The Netherlands). Journal of Applied Meteorology \& Climatology, 51(6), 1046-1060.

Brenner, N., \& Schmid, C. (2014). The "urban age" in question. International Journal of Urban and Regional Research, 38(3), 731-755.

Brown, M. J., Grimmond, S., \& Ratti, C. (2001). Comparison of methodologies for computing sky view factor in urban environments. Presentted at the International Society of Environmental Hydraulics Conference, Tempe, AZ.

Chapman, L., \& Thornes, J. (2004). Real-time sky-view factor calculation and approximation. Journal of Atmospheric \& Oceanic Technology, 21(5), 730-741.

Chen, L., Ng, E., An, X., Ren, C., Lee, M., Wang, U., \& He, Z. (2012). Sky view factor analysis of street canyons and its implications for daytime intra-urban air temperature differentials in high-rise, high-density urban areas of Hong Kong: A GIS-based simulation approach. International Journal of Climatology, 32(1), 121-136.

Ewenz, C., Bennett, J., Chris Kent, V., Guan, H., \& Clay, R. (2012). Urban heat island mapping in Adelaide. Paper presented at TREENET 13th National Street Tree Symposium. Adelaide, Australia.

Gal, T., Lindberg, F., \& Unger, J. (2009). Computing continuous sky view factors using 3D urban raster and vector databases: Comparison and application to urban climate. Theoretical and applied climatology, 95(1/2), 111-123.

Grant, R. H., Heisler, G. M., \& Gao, W. (2002). Estimation of pedestrian level UV exposure under trees. Photochemistry and Photobiology, 75(4), 369-376.

Grimmond, C., Potter, S., Zutter, H., \& Souch, C. (2001). Rapid methods to estimate sky-view factors applied to urban areas. International Journal of Climatology, 21(7), 903-913.

Grosch, T. (2005). Differential photon mapping: Consistent augmentation of photographs with correction of all light paths. In J. Dingliana \& F. Ganovelli (Eds.), Eurographics: EG short presentations (pp. 53-56). Switzerland: The Eurographics Association.

Holmer, B., Postgård, U., \& Eriksson, M. (2001). Sky view factors in forest canopies calculated with IDRISI. Theoretical and Applied Climatology, 68(1/2), 33-40.

Ibrahim, A., Nduka, I., Iguisi, E., \& Ati, O. (2011). An assessement of the impact of Sky View Factor (SVF) on the micro-climate of urban Kano. Australian Journal of Basic \& Applied Sciences, 5(7).

Johnson, D. (1985). Urban modification of diurnal tem- perature cycles in Birmingham, UK. Journal of climatology, 5(2), 221-225.

Johnson, G. T., \& Watson, I. D. (1984). The determination of view-factors in urban canyons. Journal of Climate and Applied Meteorology, 23(2), 329-335.

Kakon, A. N., \& Nobuo, M. (2009). The sky view factor effect on the microclimate of a city environment: A case study of Dhaka city. In Proceedings of the 7th International Conference on Urban Climate, June (pp. 1-4). Yokohama, Japan.

Kastendeuch, P. P. (2013). A method to estimate sky view factors from digital elevation models. International Journal of Climatology, 33(6), 1574-1578.

Kidd, C., \& Chapman, L. (2012). Derivation of sky-view factors from lidar data. International Journal of Remote Sensing, 33(11), 3640-3652.

Kokalj, Ž., Zakšek, K., \& Oštir, K. (2011). Application of sky-view factor for the visualisation of historic landscape features in lidar-derived relief models. Antiquity, 85(327).

Koolhaas, R., Obrist, H.-U., Boeri, S., Kwinter, S., \& Tazi, N. (2001). Mutations. Bordeaux and Barcelona: Arc en rêve centre d'architecture and ACTAR.

Lass, W., Haas, A., Hinkel, J., \& Jaeger, C. (2013). Avoiding the avoidable: Towards a European heat waves risk governance. Integrated Risk Governance, 2(1), 1-14.

Levermore, G., \& Cheung, H. (2012). A low-order canyon model to estimate the influence of canyon shape on the maximum urban heat island effect. Building Services Engineering Research and Technology, 33(4), 371-385.

Li, D., \& Bou-Zeid, E. (2013). Synergistic interactions between urban heat islands and heat waves: The impact in cities is larger than the sum of its parts. Journal of Applied Meteorology \& Climatology, 52(9), 2051-2064.

Lindberg, F. (2005). Towards the use of local governmental 3-D data within urban climatology studies. Mapping and Image Science, 2, 32-37.

Mills, G. (2004). The urban canopy layer heat island. IAUC Teaching Resources.

Murdock, K. L. (2012). Autodesk 3ds Max 2013 Bible (Vol. 813). New York: John Wiley \& Sons.

Oke, T. R. (1981). Canyon geometry and the nocturnal urban heat island: Comparison of scale model and field observations. Journal of Climatology, 1(3), 237-254.

Oke, T. R. (1988). Street design and urban canopy layer climate. Energy and Buildings, 11(1), 103-113.

Panão, M. J. O., Gonçalves, H. J., \& Ferrão, P. M. (2008). Optimization of the urban building efficiency potential for mid-latitude climates using a genetic algorithm approach. Renewable Energy, 33(5), 887-896.

Patz, J. A., Campbell-Lendrum, D., Holloway, T., \& Foley, J. A. (2005). Impact of regional climate change on human health. Nature, 438(7066), 310-317.

Ratti, C., Baker, N., \& Steemers, K. (2005). Energy consumption and urban texture. Energy and buildings, 37(7), 762-776. 
Ratti, C., \& Richens, P. (1999). Urban texture analysis with image processing techniques. In Computers in Building (pp. 49-64). New York: Springer.

Ratti, C., \& Richens, P. (2004). Raster analysis of urban form. Environment and Planning B: Planning and Design, 31(2), 297-309.

Reinhart, C., \& Breton, P.- F. (2009). Experimental validation of 3ds Max ${ }^{\circledR}$ Design 2009 and Daysim 3.0. Manuscript submitted for publication .

Rode, P. (2013). Trends and challenges: Global urbanisation and urban mobility. In Megacity mobility culture: How cities move in a diverse world (pp. 3-21). Berlin and New York: Springer.

Shao, B., Zhang, M., Mi, Q., \& Xiang, N. (2011). Prediction and visualization for urban heat island simulation. In Lecture notes in computer science. Computer animation and social agents; Transactions on edutainment VI (pp. 1-11). Heidelberg and Berlin: Springer.

Souza, L. C. L., Rodrigues, D. S., \& Mendes, J. F. (2003). A 3D-gis extensionf for sky view factors assessment in urban environment. In International Conference on Computers in Urban Planning and Urban Management (CUPUM'03) (pp. 1-13). Sendai, Japan: CEC-PT: Comunicações a Conferências Internacionais.

Tan, J., Zheng, Y., Tang, X., Guo, C., Li, L., Song, G., Zhen, $X$., et al. (2010). The urban heat island and its impact on heat waves and human health in Shanghai. International Journal of Biometeorology, 54(1), 75-84.

Unger, J. (2009). Connection between urban heat island and sky view factor approximated by a software tool on a 3D urban database. International Journal of Environment and Pollution, 36(1), 59-80.

US Environmental Protection Agency. (2008). Reducing urban heat islands: Compendium of strategies
(Vol. 12). Cincinnati, OH: Climate Protection Partnership Division in the U.S. Environmental Protection Agency's Office of Atmospheric Programs.

White, M., \& Kimm, G. (2015). Measuring sky view factor of urban canyons using hacked Gopro hemispheric video processing. In R. H. Crawford \& A. Stephan (Eds.), Research for a better built environment: 49th International Conference of the Architectural Science Association 2015 (pp. 525-535). Melbourne: Faculty of Architecture, Building and Planning, University of Melbourne. Retrieved from http://apo.org.au/node/ 61762

White, M., \& Langenheim, N. (2014a). Impact assessment of street trees in the City of Melbourne using temporal high polygon 3D canopy modelling. Paper presented at the 7th International Urban Design Conference Designing Productive Cities, Adelaide, Australia.

White, M., \& Langenheim, N. (2014b). Measuring urban canyons with real-time light based sky view factor modelling. In V. Oliveira, P. Pinho, L. Batista, \& T. Patatas (Eds.), Our common future in urban morphology: 21st International Seminar on Urban Form: ISUF2014 (pp. 239-304). Porto: Faculdade de Engenharia da Universidade do Porto.

Wu, J. M., Zhang, Y. M., \& Meng, Q. (2013). Calculation method of sky view factor based on RhinoGrasshopper platform. In 13th Conference of International Building Performance Simulation Association, Chambery, France, August 26 (Vol. 28). IBPSA.

Yu, S., Austern, G., Jirathiyut, T., \& Moral, M. (2014). Climatic formations: Evolutionary dynamics of urban morphologies. Journal of Asian Architecture and Building Engineering, 13(2), 317-324.

\section{About the Authors}

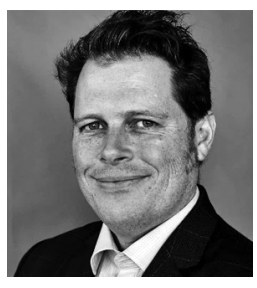

Marcus White is an award winning architect and urban designer, co-director of Harrison and White, leader the Master of Urban Design Program at the University of Melbourne, and founder of the SpatioTemporal Research Urban Design Laboratory (STRUDL). Marcus focuses on research for design involving development of new approaches for designing more liveable cities, taking advantage of data and emerging digital technologies; and research by design, where he does the act of design as a way of exploring and testing new tools and approaches spatially through projects.
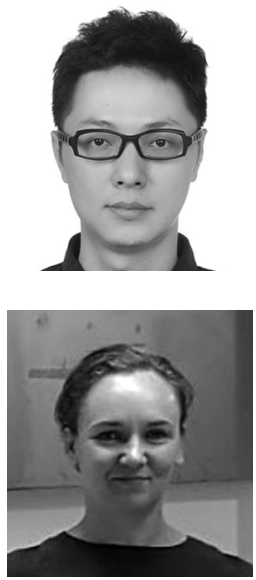

Youpei Hu is an Associate Professor of architecture theory and design in School of architecture and urban planning, Nanjing University, China. He mainly engages in the field of quantity study of urban forms and CAAD, especially on performance-oriented design optimization. He has published more than 20 research papers, including proceedings of academic conferences and academic journals, participated in several national research projects, and presided over two youth researcher projects found by Chinese National Science Foundation.

Nano Langenheim is an award winning landscape architect and horticulturist working on research relating to data visualisation and parametric modelling for advocacy and decision making support in complex urban environments responding to densification and climate change. Utilizing large scale governmental data bases, she develops 3D and 4D city models which include botanically accurate morphological trees in urban environments to maximize canopy cover and pedestrian/cyclist comfort. 

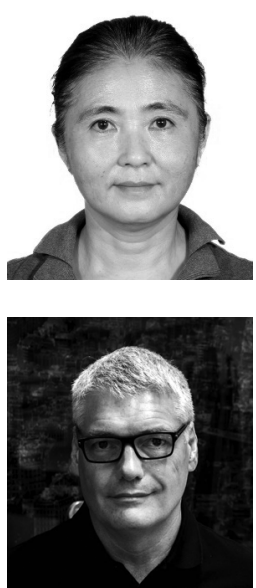

Wowo Ding is the Dean of School of the Architecture and Urban Planning at Nanjing University. She had been the recipient of multiple teaching, practice and research awards in architecture and urban design. She is a Council Member of the Chinese Architects Association-ASC, Urban Design AssociationASC and the International Seminar of Urban Morphology. Her current research focuses on the correlation between urban form and microclimate, cooperating with professors from NJU Physical Sciences and Atmospheric Sciences.

Mark Burry is Professor of Urban Futures at the University of Melbourne. His research spans across the whole of the architecture discipline with an emphasis on the role of technology within the profession, including its economic, social, historical and cultural implications. His research extends to the broader dimensions of design beyond architecture, especially speculations on the future urban condition. Typically his research has a practice base to it allowing him to promote design research within the studio from a platform of high level real-world know-how. 